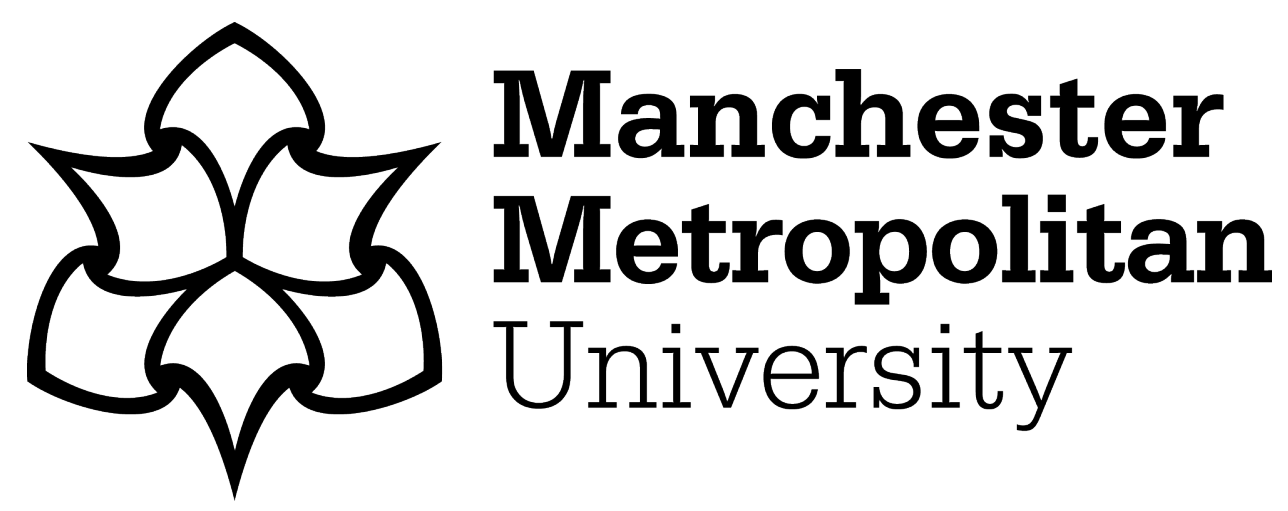

Ryan, Declan, Wullems, Jorgen, Stebbings, Georgina ORCID logoORCID: https://orcid.org/0000-0003-0706-2864, Morse, Christopher ORCID logoORCID: https://orcid.org/0000-0002-5261-2637, Stewart, Claire and OnambelePearson, Gladys (2018) Segregating the Distinct Effects of Sedentary Behavior and Physical Activity on Older Adults' Cardiovascular Structure and Function: Part 1-Linear Regression Analysis Approach. Journal of Physical Activity and Health, 15 (7). pp. 499-509. ISSN 1543-3080

Downloaded from: https://e-space.mmu.ac.uk/620841/

Version: Accepted Version

Publisher: Human Kinetics

DOI: https://doi.org/10.1123/jpah.2017-0325

Please cite the published version 


\title{
Segregating the Distinct Effects of Sedentary Behavior and Physical Activity on Older Adults' Cardiovascular Structure and Function: Part 1-Linear Regression Analysis Approach
}

\author{
Declan Ryan, Jorgen Wullems, Georgina Stebbings, Christopher Morse, Claire Stewart, \\ and Gladys Onambele-Pearson
}

\begin{abstract}
Background: Physical behavior [PB, physical activity (PA), and sedentary behavior (SB)] can adjust cardiovascular mortality risk in older adults. The aim of this study was to predict cardiovascular parameters (CVPs) using 21 parameters of PB. Methods: Participants [ $n=93,73.8(6.23)$ y] wore a thigh-mounted accelerometer for 7 days. Phenotype of the carotid, brachial, and popliteal arteries was conducted using ultrasound. Results: Sedentary behavior was associated with one of the 19 CVPs. Standing and light-intensity PA was associated with 3 and 1 CVP, respectively. Our prediction model suggested that an hourly increase in light-intensity PA would be negatively associated with popliteal intima-media thickness $[0.09 \mathrm{~mm}$ ( $95 \%$ confidence interval, 0.15 to 0.03 )]. sMVPA [moderate-vigorous PA (MVPA), accumulated in bouts $<10 \mathrm{~min}$ ] was associated with $1 \mathrm{CVP}$. ${ }_{10} \mathrm{MVPA}$ (MVPA accumulated in bouts $\geq 10 \mathrm{~min}$ ) had no associations. W50\% had associations with 3 CVP. SB\%, alpha, true mean PA bout, daily sum of PA bout time, and total week ${ }_{10}$ MVPA each were associated with 2 CVP. Conclusions: Patterns of PB are more robust predictors of CVP than PB (hours per day). The prediction that popliteal intima-media thickness would be negatively associated with increased standing and light-intensity PA engagement suggests that older adults could obtain health benefits without MVPA engagement.
\end{abstract}

Keywords: accelerometry, sitting/standing, epidemiology, gerontology

Cardiovascular-related deaths in the United Kingdom have increased $\sim 1.8$-fold per decade for those aged 55-85 years or older. ${ }^{1}$ This dramatic increase is likely to augment the socioeconomic burden as people older than 60 years are expected to account for $25 \%$ of the population by the year $2035 .{ }^{2}$ Physical activity (PA) -more specifically, moderate-vigorous PA (MVPA) - has been shown to be successful in reducing the risks and treatment of cardiovascular diseases (CVDs), and, therefore, it is recommended in government policies. UK government recommends that older adults engage in bouts of at least 10 minutes of continuous MVPA that accumulates to a minimum of 150 minutes over a week. ${ }^{3}$ MVPA engagement has shown reductions in cardiovascular parameters that can be a precursor of CVD, such as intima-media thickness (IMT) ${ }^{4}$ and artery diameter. ${ }^{5}$ At multiple locations, for example, carotid and popliteal arteries, an increase in IMT and artery diameter can be signs of increased stiffness ${ }^{6}$ and CVD risk. ${ }^{7-9}$ In 2011, the government recommendations on PA were updated to highlight the need to also avoid bouts of prolonged sedentary behavior (SB) in light of the increased awareness of the independent effects of SB on health. ${ }^{10-12}$ However, this initial recommendation was made in the absence of any clear evidence of the metabolic and/or circulatory consequences of prolonged SB in older adults. As such, it was not possible to provide a quantitative recommendation for SB time. Timely and recent evidence highlights the degree to which increments in SB time and other SB measures (eg, breaks in SB) affect cardiovascular health

Ryan, Wullems, Stebbings, Morse, and Onambele-Pearson are with the Dept of Exercise and Sport Science, Manchester Metropolitan University, Crewe, United Kingdom. Stewart is with the Research Institute for Sport and Exercise Sciences, Liverpool John Moores University, Liverpool, United Kingdom. Ryan (declan. ryan@stu.mmu.ac.uk) is corresponding author. independent of MVPA engagement. ${ }^{11-16}$ Thus, it has been proposed that low-intensity PA [standing and light-intensity PA (LIPA)] could be used to reduce SB time and improve heath, ${ }^{17,18}$ either directly or indirectly.

With technological improvements, it is now possible to accurately quantify the physical behavior (PB) levels (SB and PA time). Thigh-mounted triaxial accelerometers are considered the gold standard for SB time quantification as posture can be determined through recognizing the positional orientation of the upper leg relative to the Earth's surface and monitoring can be carried out in real time over a number of days. However, few key cardiovascular parameters have been mapped against this gold standard method of SB quantification. ${ }^{19,20}$ In addition to the accurate quantification of $\mathrm{PB}$, the patterns in which $\mathrm{PB}(\mathrm{s})$ are accumulated have become a focus of studies because of their associations with health in younger populations. ${ }^{16,21-23}$ Furthermore, a newly formulated PB quantifier, such as W50\%, represents a specific SB bout duration where the sum of SB bouts of that length or greater would accumulate $50 \%$ of total SB time. Another PB quantifier, alpha, represents the decrease in average SB bout length as the number of SB bouts increases. ${ }^{24,25}$ Associations with health have been found in few studies that have measured W50\% and alpha. ${ }^{22,26}$ However, further analysis of $\mathrm{W} 50 \%$ and alpha is needed to strengthen relevance to physiological, health, and well-being outcomes.

Therefore, the aim of the first part of this 2-part series was to determine the degree of association between thigh-mounted accelerometer measures of habitual PB and key cardiovascular parameters in older adults. The objectives of this study were 3-fold: (1) to determine whether measures of daily PB predict older adults' cardiovascular profile; (2) to determine which measures of PB patterns are better predictors of cardiovascular profile; and (3) to highlight any effects of SB on cardiovascular health that are 
independent of MVPA and vice versa. The aim of this study was to provide an evidence-based recommendation for the parameter of PB that is the most prolific predictor of cardiovascular profile. It was broadly hypothesized that SB would be independently associated with certain cardiovascular parameters of older adults, as has been shown in previous studies of middle-aged adults, ${ }^{16,27}$ so that an objective lifestyle recommendation of SB may have to consider both amount and pattern of SB accumulation to ultimately improve health. In addition, given that a number of PAs are significantly associated with cardiovascular health, this would tend to strengthen the evidence base for government PA guidelines. Specifically, our data would suggest that government PA guidelines aimed at older adults should be inclusive of recommendations for every PA intensity, not just MVPA as is currently the norm.

\section{Methods}

Ninety-three older participants [73.8 (6.23) y, 60-89 y, 55\% female] whose screening questionnaire revealed as independently mobile (did not require a wheelchair or Zimmer frame), who did not suffer from an untreated CVD, who had not sustained an injury within the preceding 3 months, who had not ever/recently suffered from a neurological disease that impaired motor control or academic ability, and who were not diabetic were recruited for this study. These participants were specifically recruited for the study through convenience sampling in the local area. Participants were contacted through older adult community groups (ranging from recreation sports to luncheon groups) to maximize the catchment area and footfall of the study within 29 miles of the local university campus. The local University (Manchester Metropolitan University) ethics subcommittee granted ethical approval. Participant approval was acquired through written informed consent. Data collection took place between January 2015 and June 2016. Participants visited the laboratory on 2 occasions separated by a minimum of 7 days, the details of which are outlined in below sections.

\section{First Laboratory Visit}

On the first visit, participant demographics were collected (Online Supplementary Table 1) and test protocol familiarization was conducted. Participants were fitted with a commercially available thigh-mounted (anterior aspect, at $50 \%$ of greater trochanter to femoral condyle distance) triaxial accelerometer (GENEA, GENEActiv Original; Activinsights Ltd, Kimbolton, United Kingdom) using a waterproof adhesive patch (Tegaderm film; 3M, North Ryde, Australia) on their dominant leg, which remained in place for 7 consecutive, free-living days. Standing leg preference during a single-leg balance exercise determined leg dominance. GENEA data (60.0-Hz frequency) were smoothed using 10-second epochs. Residual $\mathrm{G}$ was selected as the GENEA output, (Residual $\mathrm{G}=\sqrt{ }\left([\text { standard deviation } x]^{2}+[\text { standard deviation } y]^{2}+\right.$ $\left.[\text { standard deviation } z]^{2}\right)$ ), adapted from our previous work on total movement analysis in older persons ${ }^{28}$ and termed the Cheshire Algorithm for Sedentarism.

The SB-LIPA [1.50 metabolic equivalent tasks (METs)] cutoff point was 0.057 Residual G and the LIPA-MVPA (3.00 METs) cutoff point was 0.216 Residual G. PA was classified as "standing" if posture orientation was PA, but the Residual G was below the SBLIPA cutoff point. To obtain these cutoff points, a systematic validation of the GENEA against expired gas during a laboratorybased activity calibration protocol was carried out in a subsample of older adults $(n=20)$. Thus, 10 ambulatory functions [ie, 1, lying down; 2, sitting; 3 , standing quietly; 4, repeated side-stepping; 5 , self-selected speed ground walking; $6,3.5 \mathrm{~km} / \mathrm{h}$ walk on treadmill; 7 , self-selected speed walk on treadmill; 8, self-selected speed weighted-vest treadmill walking (at $15 \%$ of body weight); 9 , selfselected speed brisk walk on treadmill; and 10, cycling] were monitored with concurrent gas analyses, heart rate, motion analysis, and accelerometer output. The scatterplot exhibited a strong explained variance between Residual G (GENEA) and METs (expired gas; $\left.r^{2}=.89, P<.001\right)$. Postural identification using accelerometer axes orientation, similar to that developed by Rowlands et al, ${ }^{29}$ showed perfect agreement with known time spent in SB (6.00 $\mathrm{min})$ and PA (21.0 $\mathrm{min})$ postures during the laboratory-based activity calibration protocol [Cohen's $\kappa=1.00 ; 95 \%$ confidence interval $(\mathrm{CI}), 1.0$ to $1.0 ; P<.001]$. Residual $\mathrm{G}$ cutoff points and MET thresholds had a strong agreement for PB intensity identification (Cohen's $\kappa=0.81 ; 95 \% \mathrm{CI}, 0.49$ to $1.31 ; P<.001$ ). To help account for individual differences in physical fitness, 1 MET was equal to the resting metabolic rate of the participant.

Participants were provided with a self-report sleep diary (wake-up time, lights-off, go to sleep time, and naps not included) and were requested to complete it throughout the GENEA data collection week. GENEA outcome variables and definitions are provided in Online Supplementary Table 2. Three participants were removed from the analyses for not having sufficient accelerometer data $(\geq 6 \mathrm{~d})$.

Hydration guidance was provided as participants were asked to arrive at the second laboratory visit not only in a fasted state $(>8 \mathrm{~h})$ but also in a hydrated state as this could influence vascular parameters.

\section{Second Laboratory Visit}

Participants arrived for the second laboratory visit in a fasted, hydrated state. Where appropriate, participants were asked to refrain from taking medication until testing had been completed. All participants refrained from taking medication prior to the completion of the laboratory tests. A standardized meal $(43.0 \%$ carbohydrate, $43.0 \%$ protein, and $14.0 \%$ fat) was provided to participants before commencing the testing session.

A 3-lead electrocardiogram was fitted to participants to allow for R-gated artery analysis and resting heart rate measures. The skin was cleaned with an alcohol wipe prior to electrode (BlueSensor M; Ambu, Copenhagen, Denmark) placement. Participants began testing by resting in the supine position for 15 minutes to minimize any impact of orthostatic changes. Room temperature and light intensity were maintained at $22.0^{\circ} \mathrm{C}$ and $20.0 \mathrm{~lm} \cdot \mathrm{ft}^{2}$ (Sekonic Studio Deluxe III L-398A Light Meter; Sekonic, Staffordshire, United Kingdom), respectively, to minimize any impact of environmental ambience variations. Supine blood pressure (BP; M2 HEM-7121-F; OMRON, Hoofddorp, The Netherlands) was assessed 3 times to obtain an average systolic BP, diastolic BP, and pulse pressure.

Hydration was assessed using bioelectrical impedance analysis (Bodystat 1500; Bodystat, Douglas, United Kingdom). The bioelectrical impedance analysis assessed total body water as a percentage of total body mass using the manufacturer's own algorithms that accounted for sex, age (years), height (centimeters), and body mass (kilograms). Bioelectrical impedance analysis has been shown to be a reliable ${ }^{30}$ and valid ${ }^{31}$ method for hydration assessment. Participants were hydrated if total body water as a percentage of total body mass was $55.0 \%-65.0 \%$ for males or $50.0 \%-60.0 \%$ for females. 


\section{Baseline Vascular Assessment}

Ultrasound assessments were performed using an echo Doppler ultrasound machine (model AU5; Esaote, Genova, Italy) with a $7.50-\mathrm{MHz}$ broadband linear array transducer in brightness or B-mode with an angle of insonnation of $60.0^{\circ 32}$ [B gain: 75.0; Doppler gain: 49.0; color flow mode gain: 47.0; depth of penetration: $49.3 \mathrm{~mm}$; and depth of focus: $27.0-31.0]$. Live streaming of all assessments were collected on a Hewlett-Packard computer running video capture software (Premier 6.0; Adobe Systems, San Jose, CA) through an analog to digital converter (Pinnacle; Corel Inc, Ottawa, Canada) at $25.0 \mathrm{~Hz}$. The depth of the transducer penetration was noted to allow for video scaling during off-line analyses using Brachial Analyzer (no Bland-Altman bias in reliability and low pixel error in synthetic data analysis ${ }^{33}$ ) and Carotid Analyzer (Medical Imaging Application LLC, Iowa, IA), which has shown excellent validity compared with previous methods $\left(r^{2}=.98, P<.001\right.$; Bland-Altman bias 0.04, $\left.P=.82\right) .{ }^{34}$ Participants were supine for left common carotid artery, right brachial artery, and prone for left popliteal artery baseline assessments. Video recordings were collected over 10 cardiac cycles $^{32,35}$ for the assessment of systemic peak blood velocity, IMT, artery diameter, calculation of shear rate, and resistance index (RI; Online Supplementary Table 3). All structural measures were obtained in a $10-\mathrm{mm}$ region of interest, which was $10 \mathrm{~mm}$ distal to the carotid bulb in the anterior and posterior longitudinal (PL) plane and $10 \mathrm{~mm}$ distal to the superior medial genicular bifurcation for the popliteal artery. ${ }^{36}$ Artery diameter measures were filtered using automated R-gating to ensure artery diameter was measured during the end-diastolic phase. Remaining frame-to-frame measurements were filtered from final analysis if they did not use at least $70 \%$ of the region of interest to measure artery diameter and/or were more than $1 \mathrm{SD}$ from the mean artery diameter. All automated measures were assessed for errors by a researcher. Measurement of carotid, popliteal, and brachial IMT was performed on the far wall as this is shown to truly reflect anatomic intima-media layer. ${ }^{37,38}$ Previous validation of ultrasound showed $6.52 \%$ underestimation of carotid far-wall IMT compared with histological measures, whereas near-wall IMT had a $25.3 \%$ overestimation in autopsies of 36 males [69.0 (8.00) y] with an intraobserver error of $5.40 \%(4.3 \%){ }^{37}$

Intraday and interday coefficients of variation (CVs) were calculated from 7 participants. Interday CVs were $4.47 \%, 1.57 \%$, and $5.33 \%$ for brachial, carotid, and popliteal artery diameter, respectively, whereas intraday $\mathrm{CVs}$ were $4.97 \%, 2.34 \%$, and $4.03 \%$ for brachial, carotid, and popliteal artery diameter, respectively. Interday CVs were $1.45 \%, 7.91 \%$, and $11.3 \%$ for brachial, carotid, and popliteal IMT, respectively, whereas intraday CVs were $3.04 \%, 3.40 \%$, and $7.04 \%$ for brachial, carotid, and popliteal IMT, respectively. Artery diameter and IMT CV should be sensitive enough to detect PA-related changes as 3 months of aerobic leg exercise caused a $9.00 \%$ increase in diameter and a $16.0 \%$ reduction in IMT. ${ }^{5}$ Blood velocity $\mathrm{CV}$ was below $20.0 \%$ for interday and intraday measures of all 3 arteries. Baseline shear rate $\mathrm{CV}$ was below $16.0 \%$ for interday and intraday measures of all 3 arteries. Both blood velocity and shear rate $\mathrm{CV}$ should be sensitive enough to detect changes caused by PA as MVPA has been shown to increase blood velocity and shear rate by $39.8 \%$ and $43.7 \%$, respectively. ${ }^{39}$ Interday and intraday CV were $5.75 \%$ and $11.1 \%$ for carotid RI, respectively. RI CV could be sensitive enough to detect PA-related changes as exercised individuals display a $6.94 \%$ lower RI compared with sedentary individuals. ${ }^{40}$

\section{Statistical Analyses}

SPSS (version 22; IBM, Armonk, NY) was used for statistical analyses. First, bivariate linear regression models were used to examine any association between PB (measured in hours per day only), covariables (including hydration status, amount of prescribed medication that primarily targets CVD, and total of prescribed medication that could influence cardiovascular profile), and cardiovascular parameters. Age is a frequently used covariate within epidemiology; however, it is suggested that aging has a minimal effect on cardiovascular profile in strictly older adult populations. ${ }^{41,42}$ In our study sample, bivariate linear regressions were used to verify the presence, or otherwise, of any associations between age and cardiovascular (Online Supplementary Table 4). Age was only used as a covariate for the single cardiovascular parameters it showed an association with (ie, brachial artery diameter). If 2 or more $\mathrm{PB}$ or covariate parameters showed predictive qualities for a cardiovascular profile, a stepwise multivariate linear regression was used to assess the association between multiple PBs (measured in hours per day only) and/or covariate parameters and their combined association with cardiovascular parameters. If SB was a predictor of a specific cardiovascular marker while MVPA (sMVPA or ${ }_{10}$ MVPA) was not, or vice versa, within bivariate or multivariate models, then it was determined that the predictive qualities of SB or MVPA were likely independent of one another. Bivariate linear regression models were also used to examine the associations between patterns of PB and cardiovascular parameters. Cardiovascular variables were natural log transformed if they were non-normally distributed (KolmogorovSmirnov or Shapiro-Wilk, $P \leq .05$ ).

GENEA outliers of daily averages were identified using box and whisker plots and subsequently removed from statistical analysis of the respective GENEA variable. The data outside of the group range (higher or lower) would be considered outliers even if they were biologically possible. The aforementioned statistical tests were then reperformed to determine whether the GENEA outliers were influencing the statistical outcomes.

Statistical significance was set at $P \leq .05$. Data are presented as mean (SD) or median (interquartile range) if parametricity was violated, unless stated otherwise.

\section{Results}

\section{GENEA}

After discounting the participants with insufficient accelerometer data $(<6 \mathrm{~d})$, the remaining participants' $\mathrm{PB}$ and patterns of $\mathrm{PB}$ parameters are outlined in Online Supplementary Table 5. Of the identified outliers, there were only 5 cases where the outlier data were lower than the mean for the respective GENEA variable, suggesting that those with the greatest amount of PA and SB (the extremes) were removed from the statistical analysis. Therefore, the remaining data were representative of an average older adult population within the local area. It is unlikely that these outliers were a source of measurement error as the data within the current study fell within the ranges of previous studies using similar participants and accelerometer placement. ${ }^{43-45}$

\section{Cardiovascular Profile}

Cardiovascular characteristics are outlined in Online Supplementary Table 1. Measurement of carotid PL and popliteal variables 
was performed on a subpopulation $[n=45 ; 22$ males and 23 females; age, 73.6 (7.17) y].

\section{Bivariate Linear PB Regressions (Measured in Hours per Day Only)}

SB showed no predictive qualities for cardiovascular parameters, whereas PA variables showed a number of associations (4 out of 19) with cardiovascular parameters (Table 1). Notably, our prediction model suggested an hour per day increase in low-intensity PA (standing and LIPA) would be negatively associated with popliteal artery diameter (standing: $-0.75 \mathrm{~mm} ; 95 \% \mathrm{CI},-1.41$ to -0.09 ) and IMT (LIPA: $-0.09 \mathrm{~mm}$; $95 \% \mathrm{CI},-0.15$ to -0.03 ). In addition, an hour increase in SMVPA was also negatively associated with popliteal IMT $(-0.06 \mathrm{~mm} ; 95 \% \mathrm{CI},-0.12$ to 0.002$)$ and resting heart rate $(-3.36 \mathrm{bpm}$; $95 \% \mathrm{CI},-5.67$ to -1.05$)$.

When GENEA outliers were removed from the data (Online Supplementary Table 6), SB was found to be a predictor of heart rate (1.58 bpm; $95 \% \mathrm{CI}, 0.17$ to 2.99$)$. Standing was also found to be a predictor of popliteal IMT $(-0.13 \mathrm{~mm} ; 95 \% \mathrm{CI},-0.22$ to -0 .03 ) with the removal of outliers (thus predicting 3 out of 19 cardiovascular parameters). LIPA as a predictor had no outliers (1 out of 19 predictions for cardiovascular parameters). sMVPA was no longer a predictor of popliteal IMT when outliers were removed (thus now predicting 1 out of 19 cardiovascular parameters). ${ }_{10} \mathrm{MVPA}$ was no longer a predictor of popliteal shear rate following the removal of outliers.

\section{Multivariate Stepwise PB Regressions (Measured in Hours per Day Only)}

Heart rate had the most PB predictors, excluding only LIPA from our prediction model. Standing explained $12.2 \%$ of the variance in heart rate while controlling for the other PB parameters in the prediction model. This was the largest partial correlation of the PB parameters included in the prediction of heart rate. There were no other cardiovascular parameters that could be predicted using multiple PB parameters (Table 1).

With the removal of GENEA outliers, SB and ${ }_{10}$ MVPA were removed from the heart rate regression model (Online Supplementary Table 6). SB and sMVPA (as well as age) became associated with brachial artery diameter, following the removal of GENEA outliers (Online Supplementary Table 6). The regression suggested that brachial artery diameter was associated with a 0.55 $\mathrm{mm}(95 \% \mathrm{CI}, 0.19$ to 0.92$)$ and $0.20-\mathrm{mm}(95 \% \mathrm{CI}, 0.02$ to 0.39$)$ increase (hours per day) in sMVPA and SB, respectively.

\section{Bivariate Linear Patterns of PB Regressions}

The predictive quality of cardiovascular parameters using patterns of PB is displayed in Online Supplementary Table 7. W50\%, SB\%, and alpha appear to be the most common predictors within the SB category, showing predictive qualities for 3,2, and 2 cardiovascular parameters (out of a possible 19), respectively (Table 2). Within the PA category, daily sum of PA bout time and standing\% showed predictive qualities for 2 cardiovascular markers (out of 19), with PA bouts, true mean PA bout, LIPA\%, sMVPA\%, and ${ }_{10}$ MVPA\% all showing predictive qualities for 1 cardiovascular parameter (out of 19; Table 2).

After the removal of outliers (Online Supplementary Table 8), $\mathrm{W} 50 \%, \mathrm{SB} \%$, and alpha remained the best predictors of cardiovascular parameters within the SB category $(3,2$, and 2 out of 19, respectively), showing no change in prediction quality. Within the PA category, true mean PA bout, daily sum of PA bout time, and total week ${ }_{10}$ MVPA showed the most predictive qualities for cardiovascular parameters ( 2 each), followed by PA bouts, ${ }_{10}$ MVPA bouts, standing\%, LIPA\%, and sMVPA\% (1 each; Online Supplementary Table 8).

Only significant associations are listed in Table 2 . The complete results can be found in Online Supplementary Table 7.

\section{Discussion}

The purpose of this study was to address the following 3 objectives: (1) determine whether measures of daily PB predict older adults' cardiovascular profile; (2) determine which measures of PB patterns are better predictors of cardiovascular profile; and (3) highlight any effects of SB on cardiovascular profile that are independent of MVPA and vice versa. It was broadly hypothesized that a number of cardiovascular parameters will be uniquely sensitive to SB and others to MVPA.

\section{PB Predicts Cardiovascular Parameters}

A lack of predictive qualities of PB relative to brachial (1 association) or carotid parameters (no association) would tend to suggest that the effects of PB may be site-specific given the number of associations elsewhere. Alternatively, our observations on the brachial and carotid arteries may be indicative of an ongoing local remodeling process, which may have masked any sensitivity to PB. This "masking" hypothesis could explain why brachial artery diameter was not associated with SB or SMVPA in isolation (owing to small individual effects), but was reliably predicted in a regression model that took both SB and sMVPA into account. Interestingly, predictive qualities relative to popliteal parameters were seen with low-intensity PA (standing and LIPA) within our models, suggesting that low-intensity PA could reduce popliteal parameters that are associated with CVD. ${ }^{9}$ Within our bivariate regression models, both an hour increase in standing and LIPA would be negatively associated with a $0.14-$ and $0.09-\mathrm{mm}$ reduction in popliteal IMT, respectively, whereas LIPA was the only PB variable included in the multivariate stepwise regression model that associated popliteal IMT with a 0.11-mm decrease per hour increase in LIPA. This finding is consistent with a training study that found popliteal IMT decreased by $0.038 \mathrm{~mm}$ over 12 weeks (18 h) of LIPA ( $30 \%$ heart rate reserve), which equated to a $0.002-\mathrm{mm}$ reduction in popliteal IMT per hour of LIPA. ${ }^{46}$ The results of the current study would have strong implications in older adults who struggle to accumulate sufficient ${ }_{10} \mathrm{MVPA}$, as they may find it easier to accumulate LIPA.

\section{Which Pattern of PB is the Best Predictor of Cardiovascular Health?}

With improvements in the objective measurement of SB, the focus of research has shifted to the patterns in which SB is accumulated rather than total SB time per se. In particular, the number of SB breaks has become a heavily researched parameter ${ }^{21,47}$ especially in acute interventions. ${ }^{17,18,48,49}$ Within the current data, SB breaks only had predictive qualities for resting heart rate, whereas other patterns of SB, W50\%, and alpha showed more predictive qualities for cardiovascular parameters (3 and 2, respectively). W50\% and alpha were first introduced by Chastin and Granat ${ }^{24}$ to create a more 
Table 1 Bivariate and Multivariate Stepwise Linear Regressions Between Physical Behavior, Covariates, and Cardiovascular Parameters

\begin{tabular}{|c|c|c|c|c|c|c|c|c|}
\hline Variable & Model & $b$ & $-95 \% \mathrm{Cl}$ & $+95 \% \mathrm{Cl}$ & $P$ & $r^{2}$ & $r^{2}$ adj. & Partial correlation \\
\hline \multirow[t]{6}{*}{ Systolic BP } & $\mathrm{SB}^{\mathrm{a}}$ & -0.39 & -2.85 & 2.06 & .75 & .001 & -.01 & \\
\hline & Standing $^{\mathrm{b}}$ & -1.27 & -9.38 & 6.82 & .75 & .001 & -.01 & \\
\hline & LIPA $^{\mathrm{c}}$ & -0.75 & -6.45 & 4.94 & .79 & .001 & -.01 & \\
\hline & sMVPA $^{\mathrm{d}}$ & 1.02 & -3.58 & 5.64 & .65 & .002 & -.01 & \\
\hline & ${ }_{10} \mathrm{MVPA}^{\mathrm{e}}$ & 1.44 & -11.7 & 14.6 & .82 & .001 & -.01 & \\
\hline & Hydration $^{\mathrm{h}}$ & -0.65 & -1.14 & -0.17 & .01 & .07 & .06 & \\
\hline \multirow[t]{6}{*}{ Log diastolic BP } & $\mathrm{SB}^{\mathrm{a}}$ & 0.001 & -0.01 & 0.01 & .93 & .00 & -.01 & \\
\hline & Standing ${ }^{\mathrm{b}}$ & -0.03 & -0.09 & 0.01 & .15 & .02 & .01 & \\
\hline & $\mathrm{LIPA}^{\mathrm{c}}$ & -0.01 & -0.05 & 0.02 & .39 & .01 & -.003 & \\
\hline & sMVPA $^{\mathrm{d}}$ & 0.01 & -0.01 & 0.04 & .37 & .01 & -.002 & \\
\hline & ${ }_{10} \mathrm{MVPA}^{\mathrm{e}}$ & -0.01 & -0.10 & 0.08 & .81 & .001 & -.01 & \\
\hline & Hydration $^{\mathrm{h}}$ & -0.004 & -0.007 & 0.00 & .03 & .05 & .04 & \\
\hline \multirow[t]{6}{*}{ Pulse pressure } & $\mathrm{SB}^{\mathrm{a}}$ & -0.45 & -2.31 & 1.39 & .62 & .003 & -.01 & \\
\hline & Standing ${ }^{\mathrm{b}}$ & 1.54 & -4.56 & 7.64 & .61 & .003 & -.01 & \\
\hline & $\mathrm{LIPA}^{\mathrm{c}}$ & 0.61 & -3.68 & 4.91 & .77 & .001 & -.01 & \\
\hline & sMVPA $^{\mathrm{d}}$ & 0.17 & -3.30 & 3.65 & .92 & .00 & -.01 & \\
\hline & ${ }_{10} \mathrm{MVPA}^{\mathrm{e}}$ & 2.48 & -7.44 & 12.4 & .62 & .003 & -.01 & \\
\hline & Hydration $^{\text {h }}$ & -0.39 & -0.75 & -0.02 & .03 & .04 & .03 & \\
\hline \multirow[t]{10}{*}{ Heart rate } & $\mathrm{SB}^{\mathrm{a}}$ & 1.10 & -0.16 & 2.37 & .08 & .03 & .02 & \\
\hline & Standing $^{\mathrm{b}}$ & -5.59 & -9.67 & -1.52 & .01 & .07 & .06 & \\
\hline & LIPA $^{c}$ & -2.74 & -5.67 & 0.18 & .06 & .03 & .02 & \\
\hline & sMVPA $^{\mathrm{d}}$ & -3.36 & -5.67 & -1.05 & .01 & .08 & .07 & \\
\hline & ${ }_{10} \mathrm{MVPA}^{\mathrm{e}}$ & -6.66 & -13.4 & 0.10 & .05 & .04 & .03 & \\
\hline & $\mathrm{MR}^{\mathrm{dbae}}$ & $-6.02^{d}$ & $-9.54^{\mathrm{d}}$ & $-2.50^{d}$ & $.001^{d}$ & .22 & .19 & $-.34^{\mathrm{d}}$ \\
\hline & & $-8.50^{b}$ & $-13.4^{b}$ & $-3.57^{b}$ & $.001^{\mathrm{b}}$ & & & $-.34^{\mathrm{b}}$ \\
\hline & & $-3.01^{a}$ & $-5.23^{\mathrm{a}}$ & $-0.78^{a}$ & $.01^{\mathrm{a}}$ & & & $-.28^{\mathrm{a}}$ \\
\hline & & $-6.84^{e}$ & $-13.1^{\mathrm{e}}$ & $-0.53^{\mathrm{e}}$ & $.03^{\mathrm{e}}$ & & & $-.22^{\mathrm{e}}$ \\
\hline & & & & & $.00^{\mathrm{dbae}}$ & & & \\
\hline \multicolumn{9}{|l|}{ Brachial } \\
\hline \multirow[t]{10}{*}{ Artery diameter } & $\mathrm{SB}^{\mathrm{a}}$ & 0.002 & -0.10 & 0.10 & .97 & .00 & -.01 & \\
\hline & Standing $^{\mathrm{b}}$ & 0.08 & -0.26 & 0.43 & .63 & .003 & -.01 & \\
\hline & LIPA $^{c}$ & 0.02 & -0.22 & 0.26 & .88 & .00 & -.01 & \\
\hline & sMVPA $^{d}$ & 0.05 & -0.14 & 0.25 & .59 & .003 & -.01 & \\
\hline & ${ }_{10} \mathrm{MVPA}^{\mathrm{e}}$ & 0.02 & -0.54 & 0.58 & .94 & .00 & -.01 & \\
\hline & Primary CVD meds ${ }^{\mathrm{f}}$ & 0.09 & 0.01 & 0.19 & .03 & .04 & .03 & \\
\hline & Hydration $^{\mathrm{h}}$ & 0.02 & 0.003 & 0.04 & .02 & .05 & .04 & \\
\hline & $\mathrm{MR}^{\mathrm{ih}}$ & $\mathbf{0 . 0 3}{ }^{\mathrm{i}}$ & $0.00^{i}$ & $0.05^{\mathrm{i}}$ & $.02^{\mathrm{i}}$ & .12 & .10 & $.25^{\mathrm{i}}$ \\
\hline & & $0.02^{h}$ & $0.00^{h}$ & $0.05^{h}$ & $.03^{h}$ & & & $.24^{\mathrm{h}}$ \\
\hline & & & & & $.01^{\text {ih }}$ & & & \\
\hline \multirow[t]{5}{*}{ Log blood velocity } & $\mathrm{SB}^{\mathrm{a}}$ & -0.01 & -0.04 & 0.03 & .80 & .001 & -.01 & \\
\hline & Standing ${ }^{\mathrm{b}}$ & -0.06 & -0.14 & 0.12 & .92 & .00 & -.01 & \\
\hline & $\operatorname{LIPA}^{\mathrm{c}}$ & -0.03 & -0.12 & 0.06 & .50 & .01 & -.01 & \\
\hline & sMVPA $^{\mathrm{d}}$ & 0.04 & -0.03 & 0.11 & .28 & .01 & .002 & \\
\hline & ${ }_{10} \mathrm{MVPA}^{\mathrm{e}}$ & 0.03 & -0.18 & 0.25 & .75 & .03 & .001 & \\
\hline \multirow[t]{5}{*}{ Log shear rate } & $\mathrm{SB}^{\mathrm{a}}$ & -0.002 & -0.05 & 0.04 & .94 & .00 & -.01 & \\
\hline & Standing ${ }^{\mathrm{b}}$ & -0.04 & -0.20 & 0.11 & .58 & .003 & -.01 & \\
\hline & $\mathrm{LIPA}^{\mathrm{c}}$ & -0.04 & -0.15 & 0.06 & .41 & .01 & -.004 & \\
\hline & sMVPA $^{\mathrm{d}}$ & 0.02 & -0.06 & 0.11 & .57 & .004 & -.01 & \\
\hline & ${ }_{10} \mathrm{MVPA}^{\mathrm{e}}$ & 0.01 & -0.24 & 0.27 & .91 & .00 & -.01 & \\
\hline
\end{tabular}


Table 1 (continued)

\begin{tabular}{|c|c|c|c|c|c|c|c|c|}
\hline Variable & Model & $b$ & $-95 \% \mathrm{CI}$ & $+95 \% \mathrm{Cl}$ & $P$ & $r^{2}$ & $r^{2}$ adj. & Partial correlation \\
\hline \multirow[t]{5}{*}{ Log IMT } & $\mathrm{SB}^{\mathrm{a}}$ & 0.01 & -0.02 & 0.03 & .77 & .001 & -.01 & \\
\hline & Standing $^{\mathrm{b}}$ & 0.04 & -0.06 & 0.16 & .37 & .01 & -.002 & \\
\hline & $\mathrm{LIPA}^{\mathrm{c}}$ & 0.01 & -0.06 & 0.09 & .68 & .002 & -.01 & \\
\hline & sMVPA $^{\mathrm{d}}$ & 0.003 & 0.06 & 0.06 & .92 & .00 & -.01 & \\
\hline & ${ }_{10} \mathrm{MVPA}^{\mathrm{e}}$ & -0.06 & -0.24 & 0.11 & .48 & .01 & -.01 & \\
\hline \multicolumn{9}{|l|}{ Carotid } \\
\hline \multirow[t]{6}{*}{ AL artery diameter } & $\mathrm{SB}^{\mathrm{a}}$ & 0.07 & -0.05 & 0.19 & .26 & .01 & .003 & \\
\hline & Standing $^{\mathrm{b}}$ & -0.12 & -0.54 & 0.28 & .53 & .01 & -.01 & \\
\hline & $\mathrm{LIPA}^{\mathrm{c}}$ & -0.22 & -0.50 & 0.06 & .12 & .02 & .01 & \\
\hline & sMVPA $^{\mathrm{d}}$ & 0.01 & -0.22 & 0.23 & .96 & .00 & -.01 & \\
\hline & ${ }_{10} \mathrm{MVPA}^{\mathrm{e}}$ & 0.33 & -0.33 & 1.00 & .32 & .01 & .00 & \\
\hline & Primary CVD meds ${ }^{\mathrm{f}}$ & 0.11 & 0.003 & 0.22 & .04 & .04 & .03 & \\
\hline \multirow[t]{5}{*}{ Log AL IMT } & $\mathrm{SB}^{\mathrm{a}}$ & 0.001 & -0.02 & 0.02 & .91 & .00 & -.01 & \\
\hline & Standing $^{\mathrm{b}}$ & 0.05 & -0.02 & 0.12 & .17 & .02 & .01 & \\
\hline & $\mathrm{LIPA}^{\mathrm{c}}$ & 0.01 & -0.03 & 0.07 & .50 & .01 & -.01 & \\
\hline & sMVPA $^{\mathrm{d}}$ & 0.002 & -0.04 & 0.04 & .91 & .00 & -.01 & \\
\hline & ${ }_{10} \mathrm{MVPA}^{\mathrm{e}}$ & 0.06 & -0.06 & 0.18 & .32 & .01 & .00 & \\
\hline \multirow[t]{5}{*}{ Log AL blood velocity } & $\mathrm{SB}^{\mathrm{a}}$ & -0.02 & -0.05 & 0.02 & .32 & .01 & .00 & \\
\hline & Standing $^{\mathrm{b}}$ & -0.003 & -0.13 & 0.12 & .95 & .00 & -.01 & \\
\hline & $\mathrm{LIPA}^{\mathrm{c}}$ & 0.03 & -0.05 & 0.12 & .47 & .01 & -.01 & \\
\hline & sMVPA $^{\mathrm{d}}$ & 0.04 & -0.03 & 0.11 & .25 & .01 & .004 & \\
\hline & ${ }_{10} \mathrm{MVPA}^{\mathrm{e}}$ & 0.11 & -0.10 & 0.32 & .30 & .01 & .001 & \\
\hline \multirow[t]{5}{*}{ AL shear rate } & $\mathrm{SB}^{\mathrm{a}}$ & -9.64 & -27.4 & 8.16 & .28 & .01 & .002 & \\
\hline & Standing $^{\mathrm{b}}$ & 2.95 & -56.4 & 62.3 & .92 & .000 & -.01 & \\
\hline & $\mathrm{LIPA}^{\mathrm{c}}$ & 21.8 & -19.8 & 63.5 & .30 & .01 & .001 & \\
\hline & sMVPA $^{\mathrm{d}}$ & 14.5 & -18.9 & 48.1 & .38 & .01 & -.003 & \\
\hline & ${ }_{10} \mathrm{MVPA}^{\mathrm{e}}$ & 20.7 & -76.2 & 117 & .67 & .002 & -.01 & \\
\hline \multirow[t]{5}{*}{$\log$ AL RI } & $\mathrm{SB}^{\mathrm{a}}$ & 0.001 & -0.01 & 0.01 & .90 & .01 & .00 & \\
\hline & Standing $^{\mathrm{b}}$ & 0.02 & -0.03 & 0.07 & .42 & .01 & -.004 & \\
\hline & $\mathrm{LIPA}^{\mathrm{c}}$ & 0.01 & -0.03 & 0.04 & .74 & .001 & -.01 & \\
\hline & sMVPA $^{\mathrm{d}}$ & -0.01 & -0.04 & 0.02 & .45 & .01 & -.01 & \\
\hline & ${ }_{10} \mathrm{MVPA}^{\mathrm{e}}$ & -0.05 & -0.14 & 0.03 & .24 & .01 & .004 & \\
\hline \multirow[t]{5}{*}{ PL artery diameter } & $\mathrm{SB}^{\mathrm{a}}$ & 0.07 & -0.06 & 0.20 & .28 & .03 & .01 & \\
\hline & Standing $^{\mathrm{b}}$ & -0.07 & -0.42 & 0.27 & .65 & .01 & -.02 & \\
\hline & $\mathrm{LIPA}^{\mathrm{c}}$ & -0.17 & -0.46 & 0.13 & .25 & .04 & .01 & \\
\hline & sMVPA $^{d}$ & -0.19 & -0.48 & 0.09 & .17 & .06 & .03 & \\
\hline & ${ }_{10} \mathrm{MVPA}^{\mathrm{e}}$ & 0.27 & -0.77 & 1.32 & .59 & .01 & -.02 & \\
\hline \multirow[t]{5}{*}{ PL IMT } & $\mathrm{SB}^{\mathrm{a}}$ & -0.01 & -0.05 & 0.01 & .24 & .04 & .01 & \\
\hline & Standing $^{\mathrm{b}}$ & -0.01 & -0.09 & 0.07 & .88 & .001 & -.03 & \\
\hline & $\mathrm{LIPA}^{\mathrm{c}}$ & 0.02 & -0.05 & 0.09 & .52 & .01 & -.02 & \\
\hline & sMVPA $^{d}$ & 0.01 & -0.05 & 0.08 & .64 & .01 & -.02 & \\
\hline & ${ }_{10} \mathrm{MVPA}^{\mathrm{e}}$ & 0.10 & -0.15 & 0.35 & .41 & .02 & -.01 & \\
\hline \multicolumn{9}{|l|}{ Popliteal } \\
\hline \multirow[t]{5}{*}{ Artery diameter } & $\mathrm{SB}^{\mathrm{a}}$ & 0.14 & -0.10 & 0.40 & .24 & .03 & .01 & \\
\hline & Standing $^{\mathrm{b}}$ & -0.75 & -1.41 & -0.08 & .02 & .10 & .08 & \\
\hline & $\mathrm{LIPA}^{\mathrm{c}}$ & -0.35 & -0.91 & 0.20 & .21 & .03 & .01 & \\
\hline & sMVPA $^{\mathrm{d}}$ & 0.18 & -0.37 & 0.74 & .51 & .01 & -.01 & \\
\hline & ${ }_{10} \mathrm{MVPA}^{\mathrm{e}}$ & 0.89 & -1.19 & 2.98 & .39 & .01 & -.01 & \\
\hline
\end{tabular}


Table 1 (continued)

\begin{tabular}{|c|c|c|c|c|c|c|c|c|}
\hline Variable & Model & $b$ & $-95 \% \mathrm{Cl}$ & $+95 \% \mathrm{Cl}$ & $P$ & $r^{2}$ & $r^{2}$ adj. & Partial correlation \\
\hline \multirow[t]{6}{*}{ IMT } & $\mathrm{SB}^{\mathrm{a}}$ & 0.02 & -0.003 & 0.05 & .07 & .07 & .05 & \\
\hline & Standing $^{\mathrm{b}}$ & -0.06 & -0.15 & 0.01 & .11 & .06 & .03 & \\
\hline & LIPA $^{\mathrm{c}}$ & -0.09 & -0.15 & $-\mathbf{0 . 0 3}$ & .004 & .17 & .15 & \\
\hline & sMVPA $^{\mathrm{d}}$ & -0.06 & -0.12 & -0.002 & .04 & .09 & .07 & \\
\hline & ${ }_{10} \mathrm{MVPA}^{\mathrm{e}}$ & -0.07 & -0.32 & 0.17 & .54 & .01 & -.01 & \\
\hline & $\mathrm{MR}^{\mathrm{c}}$ & -0.09 & -0.15 & -0.03 & .004 & .17 & .15 & \\
\hline \multirow[t]{6}{*}{ Log blood velocity } & $\mathrm{SB}^{\mathrm{a}}$ & 0.03 & -0.03 & 0.10 & .36 & .01 & -.004 & \\
\hline & Standing $^{\mathrm{b}}$ & -0.12 & -0.31 & 0.06 & .18 & .04 & .01 & \\
\hline & LIPA $^{\mathrm{c}}$ & -0.06 & -0.22 & 0.08 & .37 & .01 & -.01 & \\
\hline & sMVPA $^{\mathrm{d}}$ & -0.08 & -0.23 & 0.06 & .25 & .03 & .01 & \\
\hline & ${ }_{10} \mathrm{MVPA}^{\mathrm{e}}$ & -0.51 & -1.06 & 0.03 & .06 & .07 & .05 & \\
\hline & Hydration $^{\mathrm{h}}$ & -0.01 & -0.02 & -0.01 & .002 & .20 & .19 & \\
\hline \multirow[t]{7}{*}{ Log shear rate } & $\mathrm{SB}^{\mathrm{a}}$ & 0.01 & -0.07 & 0.08 & .90 & .00 & -.02 & \\
\hline & Standing $^{\mathrm{b}}$ & 0.01 & -0.21 & 0.22 & .96 & .00 & -.02 & \\
\hline & LIPA $^{\mathrm{c}}$ & -0.01 & -0.18 & 0.17 & .95 & .00 & -.02 & \\
\hline & sMVPA $^{\mathrm{d}}$ & -0.11 & -0.28 & 0.06 & .20 & .03 & .01 & \\
\hline & ${ }_{10} \mathrm{MVPA}^{\mathrm{e}}$ & -0.66 & -1.29 & $-\mathbf{0 . 0 3}$ & .04 & .09 & .07 & \\
\hline & Hydration $^{\mathrm{h}}$ & -0.01 & -0.03 & -0.004 & .01 & .14 & .12 & \\
\hline & $\mathrm{MR}^{\mathrm{h}}$ & -0.01 & -0.03 & -0.004 & .01 & .14 & .12 & \\
\hline
\end{tabular}

Note. Significant $(P \leq .05)$ bivariate and multivariate stepwise linear regression models are indicated in bold. Different superscript letters represent which and in what order physical behavior variables are included in the multivariate model.

Abbreviations: AL, anterior longitudinal; b, change in cardiovascular variable per unit increase in GENEA variable; BP, blood pressure; +95\% CI, positive $95 \%$ confidence interval; $-95 \% \mathrm{CI}$, negative $95 \%$ confidence interval; CVD, cardiovascular disease; CVD meds, change per 1 unit increase in the number of medications (in)directly targeting CVD risk; hydration, change per percent increase in total body water; IMT, intima-media thickness; LIPA, light-intensity physical activity; MR, multivariate stepwise linear regression model; ${ }_{10} \mathrm{MVPA}$, moderate-vigorous physical activity accumulated in bouts $\geq 10 \mathrm{~min}$; sMVPA, moderate-vigorous physical activity accumulated in bouts $<10$ min; PL, posterior longitudinal; primary CVD meds, change per 1 unit increase in the number of medications directly targeting CVD risk; $r^{2}$, explained variance; $r^{2}$ adj, adjusted explained variance; RI, resistance index; SB, sedentary behavior.

${ }^{\mathrm{i}}$ Adjusted for age.

sensitive measure of change in SB accumulation as SB breaks can be similar when $\mathrm{W} 50 \%$ and alpha are significantly different between the pre- and post-phases of an intervention or between groups. ${ }^{25,50} \mathrm{~W} 50 \%$ is the usual SB bout length that would accumulate $50.0 \%$ of total SB time if all of the SB bouts of that length and shorter/greater were accumulated. ${ }^{24} \mathrm{~W} 50 \%$ had predictive qualities for popliteal IMT as a minute increase in W50\% was positively associated with a $0.003-\mathrm{mm}$ increase in popliteal IMT, which may have CVD implications as those with a history of CVD have exhibited a $0.04-\mathrm{mm}$ (95\% CI, 0.03 to 0.04$)$ increase in popliteal IMT than those with no history. ${ }^{9}$ Thus, as little as a 10-minute increase in W50\% could lead to CVD complications.

Alpha is a unit-less power-law distribution that displays the increase in SB bouts as SB bout duration decreases..$^{25}$ Diastolic BP and carotid PL IMT showed predictive associations with alpha, whereas W50\% did not in the current study. The direction of these predictive models suggested that an increase in alpha (more SB bouts, shorter duration) would be associated with an increase in diastolic BP and carotid PL IMT. This is opposite to what would be understood, as brachial diastolic BP has been found to be similar between supine and orthostatic postures. ${ }^{51}$ On the other hand, orthostatic posture increases carotid circumferential wall tension compared with supine posture and is associated with an increase in carotid plaque formation, which can be expressed as an increased IMT. This suggests that the association between alpha and carotid PL IMT may be a result of more PA (orthostatic posture) due to a reduction in SB bout length. The large $95 \% \mathrm{CI}$ (0.29 to $2.90 \mathrm{~mm}$ ) in the current data may highlight the need for further data to confirm or otherwise the reported association between alpha and carotid PL IMT, as a $0.10-\mathrm{mm}$ increase in IMT can increase the relative risk of stroke by $18.0 \% .^{52}$ The association of an increase in diastolic BP with increasing alpha may hold true as more bouts of a shorter duration would indicate that the older person causes this offset by engaging in more PA where the arms are likely hanging by their side (which may be the case in gentle strolling or even chair-based exercise). In other words, there may have been PA not captured by the thigh-mounted accelerometer in the current study. This may cause a hydrostatic pressure that would subsequently increase blood pressure. ${ }^{53}$ However, the lack of association between standing and diastolic BP within the current data does not support this idea.

The current findings suggest that W50\% should be the preferred pattern of SB parameters for predicating cardiovascular risk because it had the most predictive qualities (3 qualities). In addition, W50\% is presented in minutes, which can be easily understood and explained in a "real-world" therapeutic (clinical or lifestyle) intervention settings.

Within PA patterns of PB, true mean PA bout length ${ }^{24}$ showed the most predictive qualities for cardiovascular parameters (2 qualities), where "true mean" refers to the mean duration of a PA bout succeeding antilog transformations of previously log-transformed non-normally distributed PA bout lengths. ${ }^{24}$ This adds strength to the argument that it is not the number of SB breaks that is the most important, but the complex interaction between those SB breaks and 
Table 2 Bivariate Linear Regressions Models Between Patterns of Physical Behavior and Cardiovascular Parameters

\begin{tabular}{|c|c|c|c|c|c|c|c|}
\hline Variable & Model & $b$ & $-95 \% \mathrm{Cl}$ & $+95 \% \mathrm{Cl}$ & $P$ & $r^{2}$ & $r^{2}$ adj. \\
\hline Log diastolic BP & Alpha & 0.73 & 0.10 & 1.37 & .02 & .05 & .04 \\
\hline \multirow[t]{9}{*}{ Heart rate } & SB breaks & -0.63 & -1.13 & -0.13 & .01 & .06 & .05 \\
\hline & $<5-\min \mathrm{SB}$ bout & -1.34 & -2.27 & -0.40 & .01 & .08 & .07 \\
\hline & True mean SB bout & 0.17 & 0.01 & 0.35 & .04 & .04 & .03 \\
\hline & W50\% & 0.19 & 0.17 & 0.31 & .001 & .11 & .10 \\
\hline & PA bouts & -0.63 & -1.13 & -0.13 & .01 & .06 & .05 \\
\hline & Daily sum of PA bout time & -0.03 & -0.05 & -0.01 & .001 & .11 & .10 \\
\hline & $\mathrm{SB} \%$ & 0.27 & 0.08 & 0.46 & .01 & .08 & .07 \\
\hline & Standing $\%$ & -0.80 & -1.45 & -0.15 & .01 & .06 & .05 \\
\hline & sMVPA\% & -0.41 & -0.78 & -0.04 & .02 & .05 & .04 \\
\hline \multicolumn{8}{|l|}{ Carotid } \\
\hline PL IMT & Alpha & 1.60 & 0.29 & 2.90 & .01 & .17 & .14 \\
\hline \multicolumn{8}{|l|}{ Popliteal } \\
\hline Artery diameter & Standing $\%$ & -0.12 & -0.22 & -0.01 & .02 & .11 & .09 \\
\hline \multirow[t]{5}{*}{ IMT } & W50\% & 0.003 & 0.00 & 0.01 & .04 & .09 & .07 \\
\hline & Daily sum of PA bout time & -0.001 & -0.001 & 0.00 & .001 & .15 & .13 \\
\hline & True mean PA bout & -0.01 & -0.01 & -0.001 & .02 & .11 & .09 \\
\hline & $\mathrm{SB} \%$ & 0.01 & 0.001 & 0.01 & .01 & .13 & .11 \\
\hline & LIPA\% & -0.01 & -0.02 & -0.004 & .01 & .15 & .13 \\
\hline Log blood velocity & W50\% & 0.01 & 0.00 & 0.01 & .03 & .09 & .07 \\
\hline Log shear rate & ${ }_{10} \mathrm{MVPA} \%$ & -0.10 & -0.20 & -0.001 & .04 & .08 & .06 \\
\hline
\end{tabular}

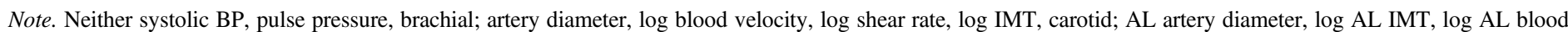

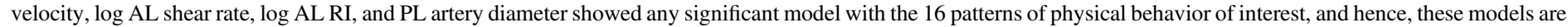

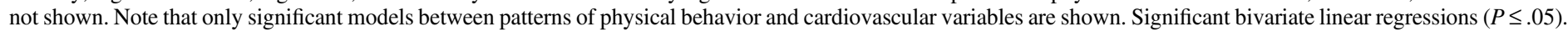

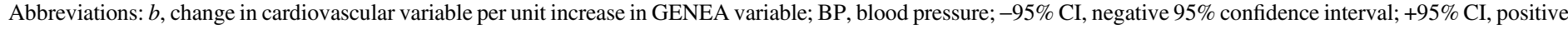

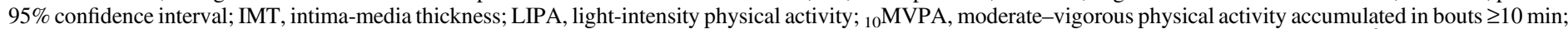

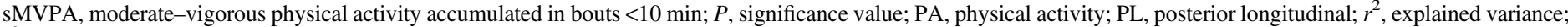
$r^{2}$ adj., adjusted explained variance; RI, resistance index; SB, sedentary behavior.

the duration of individual SB breaks. The predictive qualities of total week ${ }_{10}$ MVPA (2 qualities) and the number of ${ }_{10}$ MVPA bouts (1 quality) within the current study support the government's use of a total ${ }_{10}$ MVPA recommendation accumulated in, at least, 10minute bouts within their PA guidelines for older adults. ${ }^{3}$

\section{Independence of SB and MVPA Physiological Effects}

The basis of SB physiology stems from the apparently independent effects of SB and MVPA on health status. ${ }^{10,11}$ Prior to the removal of outliers, MVPA (sMVPA or ${ }_{10}$ MVPA) showed predictive qualities for resting heart rate, popliteal IMT, and popliteal LOG shear rate, whereas SB did not within bivariate regression models. After the removal of outliers, sMVPA only showed predictive qualities for heart rate; however, SB now displayed predictive qualities for heart rate too. This could imply that the effects of SB and MVPA on heart rate may not be independent. Furthermore, SB is excluded while sMVPA is included in the multivariate predictive model for heart rate suggesting that SB does not add any further strength to the predictive model for heart rate. This could imply that SB and SMVPA use the same mechanistic pathways to affect heart rate. MVPA is known to reduce resting heart rate through increases in stroke volume ${ }^{54}$ and reduction in peripheral resistance, ${ }^{55}$ whereas SB does the opposite. ${ }^{56,57}$ The results of the current study support the idea that SB and MVPA affect resting heart rate indirectly by impacting on stroke volume and total peripheral resistance.

The predictive qualities of W50\% and alpha were just as prevalent as those of true mean PA bout length, daily sum of PA bout time, and total week ${ }_{10}$ MVPA. Of the 6 cardiovascular markers these patterns of PB parameters predicted, 3 of them were only associated with 1 pattern of PB variable. This may imply that SB and PA parameters are physiologically independent and, as such, warrant the need for future studies to include multiple PB parameters to be able to fully assess the effect of PB on health.

The main strength of this study is the use of a thigh-mounted accelerometer, which allows for accurate posture classification. However, $1 \mathrm{~PB}$ variable this study did not measure is seated/reclined PB eliciting >1.50 METs (which would occur in seated exercise training programs, for instance, a modality of exercise of particular prevalence in frail older persons).$^{58}$ Arguably, it is unlikely that this classification of PB would be prevalent within independent living older adults and, therefore, its absence from our current PB stratification would be minimal in this type of population. It is, however, notable that owing to the age group of our study participants, the sample was skewed toward low adherence to ${ }_{10} \mathrm{MVPA}$, and hence, any relationship assessment up to that level of PA intensity would be incomplete. Arguably also, although we have been able to identify the best predictors from $21 \mathrm{~PB}$ parameters given that the highest explained variance was up to $22 \%$, it would appear that the 
cumulative effect of factors, other than PB, have a more substantial effect on the cardiovascular parameters of interest within the current study. A limitation of the current study modeling approach was that owing to the study being underpowered to examine subgroups, models did not adjust for other potential confounding variables, such as comorbidities and physical function. Future large studies should aim to account for at least these 3 key variables in their estimations of the effects of PB on cardiovascular health outcomes.

\section{Conclusions}

The purpose of this study was to determine which measures of PB display predictive qualities for cardiovascular variables so future research could justify the use of specific PB parameters as dependent variables within intervention studies. The main strength of this study is the use of a thigh-mounted accelerometer, which allows for accurate posture classification. Overall, the present study displayed that all PB measures (hours per day), excluding ${ }_{10}$ MVPA, showed predictive qualities for at least 1 cardiovascular variable. Within patterns of PB, W50\% and total week MVPA, daily sum of PA time, and true mean PA bout length were the best predictors of cardiovascular parameters. The results suggest patterns of PB are more prolific predictors of cardiovascular profile than total PB measured in hours per day. SB and MVPA PB measures showed different and unique predicative qualities for cardiovascular parameters. This observation further supports the notion that both SB and MVPA engagements need to be considered in future PB research and/or lifestyle recommendations. Finally, increasing standing and LIPA engagement showed predictive qualities for popliteal IMT reduction. We propose this to be one of the most clinically relevant findings from our current work as it suggests that older adults do not have to engage in MVPA (which they have, in any case, shown poor long-term compliance to), to gain health benefits.

\section{References}

1. Townsend N, Bhatnagar P, Wilkins E, Wickramasinghe K, Rayner M. Cardiovascular Disease Statistics 2015. London, UK: British Heart Foundation; 2015.

2. Office for National Statistics. Population Ageing in the United Kingdom, its Constituent Countries and the European Union. London, UK: UK Data Service; 2012.

3. Department of Health Social Services and Public Safety. Physical Activity Guidelines for Older Adults (65+ Years). London, UK: Department of Health Social Services and Public Safety; 2011.

4. Pahkala K, Heinonen OJ, Simell O, et al. Association of physical activity with vascular endothelial function and intima-media thickness. Circulation. 2011;124(18):1956-1963. PubMed doi:10.1161/ CIRCULATIONAHA.111.043851

5. Dinenno FA, Tanaka H, Monahan KD, et al. Regular endurance exercise induces expansive arterial remodelling in the trained limbs of healthy men. J Physiol. 2001;534(1):287-295. doi:10.1111/j.14697793.2001.00287.x

6. Debasso R, Åstrand H, Bjarnegård N, Ahlgren ÅR, Sandgren T, Länne T. The popliteal artery, an unusual muscular artery with wall properties similar to the aorta: implications for susceptibility to aneurysm formation? J Vasc Surg. 2004;39(4):836-842. PubMed doi:10.1016/j.jvs.2003.12.005

7. Bots ML, Hoes AW, Koudstaal PJ, Hofman A, Grobbee DE. Common carotid intima-media thickness and risk of stroke and myocardial infarction the Rotterdam Study. Circulation. 1997;96(5):1432-1437. PubMed doi:10.1161/01.CIR.96.5.1432

8. Bai CH, Chen JR, Chiu HC, Pan WH. Lower blood flow velocity, higher resistance index, and larger diameter of extracranial carotid arteries are associated with ischemic stroke independently of carotid atherosclerosis and cardiovascular risk factors. J Clin Ultrasound. 2007;35(6):322-330. doi:10.1002/jcu.20351

9. Burke GL, Evans GW, Riley WA, et al. Arterial wall thickness is associated with prevalent cardiovascular disease in middle-aged adults the atherosclerosis risk in communities (ARIC) study. Stroke. 1995;26(3):386-391. PubMed doi:10.1161/01.STR.26.3.386

10. Bey L, Hamilton MT. Suppression of skeletal muscle lipoprotein lipase activity during physical inactivity: a molecular reason to maintain daily low-intensity activity. J Physiol. 2003;551(2):673-682. doi:10.1113/jphysiol.2003.045591

11. Gennuso KP, Gangnon RE, Matthews CE, Thraen-Borowski KM, Colbert LH. Sedentary behavior, physical activity, and markers of health in older adults. Med Sci Sports Exerc. 2013;45(8):1493-1500. PubMed doi:10.1249/MSS.0b013e318288a1e5

12. Gennuso KP, Gangnon RE, Thraen-Borowski KM, Colbert LH. Dose-response relationships between sedentary behaviour and the metabolic syndrome and its components. Diabetologia. 2015;58(3): 485-492. PubMed doi:10.1007/s00125-014-3453-z

13. Thosar SS, Bielko SL, Mather KJ, Johnston JD, Wallace JP. Effect of prolonged sitting and breaks in sitting time on endothelial function. Med Sci Sports Exerc. 2015;47(4):843-849. PubMed doi:10.1249/ MSS.0000000000000479

14. Stamatakis E, Davis M, Stathi A, Hamer M. Associations between multiple indicators of objectively-measured and self-reported sedentary behaviour and cardiometabolic risk in older adults. Prev Med. 2012;54(1):82-87. PubMed doi:10.1016/j.ypmed.2011.10.009

15. Rezende LFM, Sá TH, Mielke GI, Viscondi JYK, Rey-López JP, Garcia LMT. All-cause mortality attributable to sitting time: analysis of 54 countries worldwide. Am J Prev Med. 2016;51(2):253-263. PubMed doi:10.1016/j.amepre.2016.01.022

16. García-Hermoso A, Martínez-Vizcaíno V, Recio-Rodríguez JI, et al. Sedentary behaviour patterns and carotid intima-media thickness in Spanish healthy adult population. Atherosclerosis. 2015;239(2): 571-576. doi:10.1016/j.atherosclerosis.2015.02.028

17. Bailey DP, Locke CD. Breaking up prolonged sitting with lightintensity walking improves postprandial glycemia, but breaking up sitting with standing does not. J Sci Med Sport. 2014;18(3):294-298. PubMed doi:10.1016/j.jsams.2014.03.008

18. Peddie MC, Bone JL, Rehrer NJ, Skeaff CM, Gray AR, Perry TL. Breaking prolonged sitting reduces postprandial glycemia in healthy, normal-weight adults: a randomized crossover trial. Am J Clin Nutr. 2013;98(2):358-366. PubMed doi:10.3945/ajcn.112.051763

19. Brocklebank LA, Falconer CL, Page AS, Perry R, Cooper AR. Accelerometer-measured sedentary time and cardiometabolic biomarkers: a systematic review. Prev Med. 2015;76:92-102. PubMed doi:10.1016/j.ypmed.2015.04.013

20. Hajduk AM, Chaudhry SI. Sedentary behavior and cardiovascular risk in older adults: a scoping review. Curr Cardiovasc Risk Rep. 2016;10(1):1-11. doi:10.1007/s12170-016-0485-6

21. Carson V, Wong SL, Winkler E, Healy GN, Colley RC, Tremblay MS. Patterns of sedentary time and cardiometabolic risk among Canadian adults. Prev Med. 2014;65:23-27. doi:10.1016/j.ypmed. 2014.04.005

22. Bellettiere J, Winkler EA, Chastin SF, et al. Associations of sitting accumulation patterns with cardio-metabolic risk biomarkers in Australian adults. PLoS ONE. 2017;12(6):e0180119. PubMed doi: 10.1371/journal.pone.0180119 
23. van der Berg JD, Stehouwer CD, Bosma H, et al. Associations of total amount and patterns of sedentary behaviour with type 2 diabetes and the metabolic syndrome: the Maastricht study. Diabetologia. 2016;59(4):709-718. PubMed doi:10.1007/s00125-015-3861-8

24. Chastin S, Granat M. Methods for objective measure, quantification and analysis of sedentary behaviour and inactivity. Gait Posture. 2010;31(1):82-86. doi:10.1016/j.gaitpost.2009.09.002

25. Chastin SF, Winkler EA, Eakin EG, et al. Sensitivity to change of objectively-derived measures of sedentary behavior. Meas Phys Educ Exerc Sci. 2015;19(3):138-147. doi:10.1080/1091367X.2015. 1050592

26. Van Roekel EH, Winkler EA, Bours MJ, et al. Associations of sedentary time and patterns of sedentary time accumulation with health-related quality of life in colorectal cancer survivors. Prev Med Rep. 2016;4:262-269. doi:10.1016/j.pmedr.2016.06.022

27. Gomez-Marcos MA, Recio-Rodríguez JI, Patino-Alonso MC, et al. Relationship between objectively measured physical activity and vascular structure and function in adults. Atherosclerosis. 2014; 234(2):366-372. doi:10.1016/j.atherosclerosis.2014.02.028

28. Onambele GL, Narici MV, Maganaris CN. Calf muscletendon properties and postural balance in old age. J Appl Physiol. 2006;100(6):2048-2056. PubMed doi:10.1152/japplphysiol.01442. 2005

29. Rowlands AV, Olds TS, Hillsdon M, et al. Assessing sedentary behavior with the GENEActiv: introducing the sedentary sphere. Med Sci Sports Exerc. 2014;46(6):1235-1247. PubMed doi:10.1249/ MSS.0000000000000224

30. Shanholtzer B, Patterson S. Fluid hydration status assessment in behavioral medicine research: seven-day test-retest reliability. Ann Behav Med. 2002;45:S134.

31. Ritz P. Bioelectrical impedance analysis estimation of water compartments in elderly diseased patients the source study. J Gerontol A Biol Sci Med Sci. 2001;56(6):M344-M348. PubMed doi:10.1093/gerona/ 56.6.M344

32. Harris RA, Nishiyama SK, Wray DW, Richardson RS. Ultrasound assessment of flow-mediated dilation. Hypertension. 2010; 55(5):1075-1085. PubMed doi:10.1161/HYPERTENSIONAHA. 110.150821

33. Sonka M, Liang W, Lauer RM. Automated analysis of brachial ultrasound image sequences: early detection of cardiovascular disease via surrogates of endothelial function. IEEE Trans Med Imaging. 2002;21(10):1271-1279. doi:10.1109/TMI.2002.806288

34. Mancini G, Abbott D, Kamimura C, Yeoh E. Validation of a new ultrasound method for the measurement of carotid artery intima medial thickness and plaque dimensions. Can $J$ Cardiol. 2004;20(13):1355-1359. PubMed

35. Gill RW. Measurement of blood flow by ultrasound: accuracy and sources of error. Ultrasound Med Biol. 1985;11(4):625-641. PubMed doi:10.1016/0301-5629(85)90035-3

36. Touboul PJ, Hennerici M, Meairs S, et al. Mannheim carotid intimamedia thickness and plaque consensus (2004-2006-2011). Cerebrovasc Dis. 2012;34(4):290-296. PubMed doi:10.1159/000343145

37. Wong M, Edelstein J, Wollman J, Bond MG. Ultrasonic-pathological comparison of the human arterial wall. Verification of intima-media thickness. Arterioscler Thromb. 1993;13(4):482-486. PubMed doi:10.1161/01.ATV.13.4.482

38. Pignoli P, Tremoli E, Poli A, Oreste P, Paoletti R. Intimal plus medial thickness of the arterial wall: a direct measurement with ultrasound imaging. Circulation. 1986;74(6):1399-1406. PubMed doi:10.1161/ 01.CIR.74.6.1399

39. Thijssen D, Dawson EA, Black MA, Hopman M, Cable NT, Green DJ. Brachial artery blood flow responses to different modalities of lower limb exercise. Med Sci Sports Exerc. 2009;41(5):1072-1079. PubMed doi:10.1249/MSS.0b013e3181923957

40. Azhim A, Katai M, Akutagawa M, et al. Exercise improved ageassociated changes in the carotid blood velocity waveforms. J Biomed Pharmaceutical Eng. 2007;1(1):17-26.

41. Benetos A, Laurent S, Hoeks A, Boutouyrie P, Safar M. Arterial alterations with aging and high blood pressure. A noninvasive study of carotid and femoral arteries. Arterioscler Thromb. 1993;13(1): 90-97. PubMed doi:10.1161/01.ATV.13.1.90

42. Flück D, Beaudin AE, Steinback CD, et al. Effects of aging on the association between cerebrovascular responses to visual stimulation, hypercapnia and arterial stiffness. Front Physiol. 2014;5:49.

43. Lord S, Chastin SFM, McInnes L, Little L, Briggs P, Rochester L. Exploring patterns of daily physical and sedentary behaviour in community-dwelling older adults. Age Ageing. 2011;40(2):205-210. PubMed doi:10.1093/ageing/afq166

44. Fitzsimons CF, Kirk A, Baker G, Michie F, Kane C, Mutrie N. Using an individualised consultation and activPAL ${ }^{\mathrm{TM}}$ feedback to reduce sedentary time in older Scottish adults: results of a feasibility and pilot study. Prev Med. 2013;57(5):718-720. PubMed doi:10.1016/j. ypmed.2013.07.017

45. Davis MG, Fox KR. Physical activity patterns assessed by accelerometry in older people. Eur J Appl Physiol. 2007;100(5):581-589. PubMed doi:10.1007/s00421-006-0320-8

46. Green DJ, Swart A, Exterkate A, et al. Impact of age, sex and exercise on brachial and popliteal artery remodelling in humans. Atherosclerosis. 2010;210(2):525-530. PubMed doi:10.1016/j.atherosclerosis. 2010.01.048

47. Chastin SF, Egerton T, Leask C, Stamatakis E. Meta-analysis of the relationship between breaks in sedentary behavior and cardiometabolic health. Obesity. 2015;23(9):1800-1810. PubMed doi:10.1002/ oby. 21180

48. Dunstan DW, Kingwell BA, Larsen R, et al. Breaking up prolonged sitting reduces postprandial glucose and insulin responses. Diabetes Care. 2012;35(5):976-983. PubMed doi:10.2337/dc11-1931

49. Holmstrup M, Fairchild T, Keslacy S, Weinstock R, Kanaley J. Multiple short bouts of exercise over 12-h period reduce glucose excursions more than an energy-matched single bout of exercise. Metabolism. 2014;63(4):510-519. PubMed doi:10.1016/j.metabol. 2013.12.006

50. Ryan DJ, Morse CI, Stebbings GK, Stewart CE, Onambele-Pearson GL. Comparing patterns of sedentary behaviour and physical activity accumulation in Sedentary, Ambulator, and Active Couch Potato older adults. Poster presented at: Proceedings of The Physiological Society; July 29-31, 2016. Dublin, Ireland. http://www.physoc.org/proceedings/ abstract/Proc\%20Physiol\%20Soc\%2037PCB171. Accessed December 10, 2016.

51. Gemignani T, Azevedo RC, Higa CM, Coelho OR, Matos-Souza JR, Nadruz W. Increased popliteal circumferential wall tension induced by orthostatic body posture is associated with local atherosclerotic plaques. Atherosclerosis. 2012;224(1):118-122. PubMed doi:10. 1016/j.atherosclerosis.2012.06.069

52. Lorenz MW, Markus HS, Bots ML, Rosvall M, Sitzer M. Prediction of clinical cardiovascular events with carotid intima-media thickness: a systematic review and meta-analysis. Circulation. 2007; 115(4):459-467. PubMed doi:10.1161/CIRCULATIONAHA.106. 628875

53. Padilla J, Sheldon RD, Sitar DM, Newcomer SC. Impact of acute exposure to increased hydrostatic pressure and reduced shear rate on conduit artery endothelial function: a limb-specific response. Am J Physiol Heart Circ Physiol. 2009;297(3):H1103-H1108. doi:10. 1152/ajpheart.00167.2009 
54. Hagberg JM, Ehsani A, Holloszy J. Effect of 12 months of intense exercise training on stroke volume in patients with coronary artery disease. Circulation. 1983;67(6):1194-1199. PubMed doi:10.1161/ 01.CIR.67.6.1194

55. Hambrecht R, Gielen S, Linke A, et al. Effects of exercise training on left ventricular function and peripheral resistance in patients with chronic heart failure: a randomized trial. JAMA. 2000;283(23): 3095-3101. PubMed doi:10.1001/jama.283.23.3095

56. Spaak J, Montmerle S, Sundblad P, Linnarsson D. Long-term bed rest-induced reductions in stroke volume during rest and exercise: cardiac dysfunction vs volume depletion. J Appl Physiol. 2005; 98(2):648-654. PubMed doi:10.1152/japplphysiol.01332.2003

57. Levine BD, Zuckerman JH, Pawelczyk JA. Cardiac atrophy after bed-rest deconditioning a nonneural mechanism for orthostatic intolerance. Circulation. 1997;96(2):517-525. doi:10.1161/01.CIR.96. 2.517

58. Yates SM, Dunnagan TA. Evaluating the effectiveness of a homebased fall risk reduction program for rural community-dwelling older adults. J Gerontol A Biol Sci Med Sci. 2001;56(4):M226-M230. doi:10.1093/gerona/56.4.M226 